\title{
Characterization and Thermal Behavior of Polymer-Modified Asphalt
}

\author{
Maria da Conceição Cavalcante Lucena, Sandra de Aguiar Soares*, \\ Jorge Barbosa Soares \\ Dept. of Organic and Inorganic Chemistry, Dept. of Transportation Engineering \\ Universidade Federal do Ceará \\ C.P. 12200, 60455-760, Fortaleza - CE, Brazil
}

Received: February 2, 2003; Revised: June 29, 2004

\begin{abstract}
A styrene-butadiene-styrene modified asphalt cement was characterized by infrared, differential scanning calorimetry, thermogravimetric analysis and empirical tests such as ring and ball softening point, penetration and elastic recovery. After aging in the rolling thin-film oven, the polymer-modified asphalt presented structural changes relating to oxidation of the material. The infrared spectra showed an increase in hydroxyl groups and the formation of carbonyl compounds and sulphoxides. The percentage of crystallized fraction calculated from differential scanning calorimetry was $0.41 \%$. Thermogravimetric analyses in inert and oxidative atmospheres revealed distinct events during thermal decomposition; the initial activation energies were similar, but changed as the process evolved.
\end{abstract}

Keywords: modified asphalt characterization, SBS copolymer, thermal degradation

\section{Introduction}

Petroleum asphaltic cement (AC) composed of aromatic hydrocarbons, paraffins and resins has been used for a variety of purposes, but most importantly for road surfacing ${ }^{1}$. Certain AC binder properties are required in this application to prevent the occurrence of three major pavement stresses, i.e., rutting, fatigue and thermal cracking. Pavement asphalt mixtures are sensitive to degradation agents such as heat, oxygen, ozone, chemicals, etc. to which they are exposed during their preparation, storage and service ${ }^{2}$. Thermo-oxidative processes lead to the formation of unstable chemical structures which may induce deterioration of the physical and chemical properties of asphaltic surfaces.

Considerable research in recent years has focused on improving the functional properties of the $\mathrm{AC}^{3}$. The use of synthetic polymers as additives, via chemical or physical blending, has been shown to greatly improve the performance of conventional asphalts ${ }^{4}$. The thermoplastic nature of these binders has displayed the ability to combine properties of elasticity, strength and adhesion to increase road life. Improved properties also include greater resistance to aging and stability at high temperatures.

Thermoplastic copolymers such as styrene-butadiene-

*e-mail: sas@ufc.br

Article presented at the XV CBECIMAT, Natal - RN, November/2002 styrene (SBS) have exhibited the greatest potential for bitumen modification ${ }^{5}$. The SBS structure consists of a triblock chain having a two-phase morphology of styrenic block domains within a matrix of polybutadiene ${ }^{6}$. The polystyrene end-blocks confer strength on the polymer, while the rubbery polybutadiene gives elasticity. When SBS is blended with $\mathrm{AC}$, it is believed the elastomeric phase of SBS absorbs the maltenes from the oil fractions, forming a continuous network. The large-scale use of these polymers may be attributed to their networks, which are due to the rheologic properties of the modified binder and the interactions of bitumen constituents that increase the complex modulus and the elastic response?

The use of SBS as an asphalt modifier was first developed by SHELL Chemical Company ${ }^{8}$. Considerable research has been done under different conditions to identify the various parameters that affect the properties of SBS modified asphalts ${ }^{9}$. Much effort has also been dedicated to establishing the parameters that determine optimum mixing conditions (bitumen source, polymer content, bitumenpolymer compatibility and aging), as well as the properties necessary to stabilize modified asphalt. 
The addition of a SBS copolymer containing soft and glassy segments such as styrene-butadiene-styrene block is expected to affect the molecular microstructure of asphaltic material. In theory, the soft segments provide greater toughness and low temperature cracking, while the hard segments improve the material's strength. The degree of modification depends on the nature of the base bitumen and on the AC-polymer compatibility. Thermal cracking, in particular, can be associated with phase separation, suggesting the immiscibility of the base bitumen and the polymer ${ }^{10}$.

CAPFLEX is a SBS asphalt binder commercialized by Petrobras for road paving applications in Brazil, where bituminous materials are characterized primarily on the basis of empirical testing methods. This article reports on a study of CAPFLEX, identifying some of the material's physical and chemical properties and its thermal behavior. Parameters such as glass transition temperature ( $\mathrm{Tg}$ ) and amount of crystallized fractions were monitored by differential scanning calorimetry (DSC) $)^{11-13}$ and these data correlated with the thermal susceptibility of pavements. The degradation of the SBS-modified asphalt was also studied using the rolling thin-film oven test (RTFOT) according to the recommendations of the Strategic Highway Research Program (SHRP) ${ }^{14}$ given in the Superior Performance Pavements (SUPERPAVE) specifications ${ }^{15}$. The aging process was monitored using techniques such as TGA and infrared (FTIR). The material was also characterized based on conventional empirical tests such as penetration ${ }^{16}$, softening point ${ }^{17}$, elastic recovery ${ }^{18}$ and viscosity at $135^{\circ} \mathrm{C}^{19}$. Thermal analysis, commonly used for polymeric systems ${ }^{20}$, was also performed using thermogravimetry (TGA) to observe the degradation process at a higher temperature and to study the kinetics. It is expected that the finding properties and parameters associated with thermal degradation should serve to underpin further studies in this area of research.

\section{Materials and Methods}

\subsection{Materials}

The AC 20 modified with 4\% of SBS (CAPFLEX) used in the present study is produced by Petrobras BR Distribuidora. The AC 20 was produced at REDUC (Refinaria Duque de Caxias) from Arabian light petroleum.

\subsection{Methods}

\subsubsection{Sampling}

The sampling of CAPFLEX for all the tests performed here followed the ASTM D140 standard ${ }^{21}$.

\subsubsection{Characterization of CAPFLEX}

The penetration test of the modified asphalt was performed at $25^{\circ} \mathrm{C}$, with a $10 \mathrm{~g}$ load applied for $5 \mathrm{~s}$ according to the ASTM
D5 specification. The softening point test was performed following the ASTM D36 to obtain the penetration index of the modified asphalt. The elastic recovery (ASTM D6084) was also determined. The viscosity at $135^{\circ} \mathrm{C}$ was measured using a Brookfield viscometer model DVII ${ }^{+}$attached to a THERMOSEL temperature controller.

\subsubsection{Oxidative Aging}

The aging was simulated in the RTFOT in accordance with the ASTM D2872 specification. Approximately $35 \mathrm{~g}$ of CAPFLEX were weighed, heated to $163{ }^{\circ} \mathrm{C}$ and held at that temperature for $85 \mathrm{~min}$, after which the volatile content was calculated.

\subsubsection{Structural Characterization by FTIR}

The structural modifications after aging were investigated by infrared spectroscopy using a Shimadzu FTIR-8300 spectrometer. The spectra of the homogenized material, in the form of $\mathrm{KBr}$ discs, were analyzed in the range of 400 to $4000 \mathrm{~cm}^{-1}$.

\subsubsection{Thermal Analysis}

\section{- DSC}

The DSC curves were performed on $10 \mathrm{mg}$ samples in an aluminum holder, under a nitrogen flow $\left(100 \mathrm{~mL} \cdot \mathrm{min}^{-1}\right)$ at a rate of $10^{\circ} \mathrm{C} \cdot \mathrm{min}^{-1}$, in the range of $-80{ }^{\circ} \mathrm{C}$ to $200{ }^{\circ} \mathrm{C}$, using a Shimadzu DSC-50 calorimeter. Glass transition and paraffin dissolution were measured in the heating curve. The percentage of crystallized fractions $\left(\% \mathrm{~F}_{\mathrm{c}}\right)$ was determined from Eq.122:

$$
\% \mathrm{~F}_{\mathrm{c}}=\left(\Delta \mathrm{H}_{\mathrm{obs}} \times 100\right) / 200
$$

where $\Delta \mathrm{H}_{\text {obs }}$ is the observed enthalpy relative to the dissolved paraffin in the CAPFLEX sample. A value of $200 \mathrm{~J} / \mathrm{g}$ was considered, based on the fusion enthalpy of n-alkanes with a chain of carbon atoms between 30 and $40^{23}$.

- TGA

Thermal decomposition was verified in $10 \mathrm{mg}$ samples in an aluminum holder under a nitrogen or air flow $\left(50 \mathrm{~cm}^{3}\right.$. $\mathrm{min}^{-1}$ ), heated from 25 to $600^{\circ} \mathrm{C}$ at varying heating rates of $5,10,20$ and $40^{\circ} \mathrm{C} \cdot \mathrm{min}^{-1}$. The TGA curves and its differential (DTG) were carried out in a Shimadzu TGA-50 thermogravimetric analyzer. The apparent activation energy as a function of the degree of decomposition in air and nitrogen atmospheres was calculated by the Ozawa method ${ }^{20}$.

\section{Results and Discussion}

\subsection{Characterization of CAPFLEX}

Table 1 compares the properties of CAPFLEX against those of unmodified AC 20.

CAPFLEX showed a greater penetration value than the 
Table 1. Comparison of CAPFLEX and AC 20.

\begin{tabular}{lccccc}
\hline Sample & $\begin{array}{c}\text { Penetration } \\
(\mathrm{dmm})\end{array}$ & $\begin{array}{c}\text { Softening Point } \\
\left({ }^{\circ} \mathrm{C}\right)\end{array}$ & $\begin{array}{c}\text { Temperature } \\
\text { Susceptibility }\end{array}$ & $\begin{array}{c}\text { Viscosity at } 135^{\circ} \mathrm{C}(\mathrm{cP}) \\
(\%)\end{array}$ & $\begin{array}{c}\text { Elastic Recovery at } \\
25^{\circ} \mathrm{C}\end{array}$ \\
\hline CAPFLEX & 70 & 51.8 & 0.1 & 825 & 62.5 \\
AC 20 & 53 & 48.8 & -1.4 & 358 & 2.5 \\
\hline
\end{tabular}

Table 2. Attribution of the FTIR main absorption bands of CAPFLEX before and after RTFOT.

\begin{tabular}{cc}
\hline Wave number $\left(\mathrm{cm}^{-1}\right)$ & $\begin{array}{c}\text { Attribution of the main } \\
\text { absorption bands }{ }^{27}\end{array}$ \\
\hline 722 & $\delta_{\mathrm{r}}\left(\mathrm{CH}_{2}\right)_{\mathrm{n}}, \mathrm{n}>4$ \\
746,814 and 874 & $\delta \mathrm{C}-\mathrm{H}$ in substituted aromatics \\
1030 & $v \mathrm{~S}=\mathrm{O}$ \\
1160 & $v \mathrm{C}-\mathrm{O}-\mathrm{C}($ anhydrides $)$ \\
1650 & $v \mathrm{C}=\mathrm{O}$ \\
2860 & $v \mathrm{C}-\mathrm{H}\left(\mathrm{CH}_{2}\right)$ \\
2960 & $v \mathrm{C}-\mathrm{H}\left(\mathrm{CH}_{3}\right)$ \\
3450 & $v \mathrm{O}-\mathrm{H}_{3}$ \\
\hline
\end{tabular}

unmodified AC, which was not expected. The penetration value typically decreases with increased copolymer content ${ }^{24}$. This unexpected result was attributed to the presence of a diluent added to the modified AC formulation. This diluent is commonly used to increase the materials' compatibility. However, as expected, the modified asphalt showed a higher softening point and absolute viscosity at $135^{\circ} \mathrm{C}^{8}$. The material's elastic properties improved with the incorporation of the polymer, with elastic recovery increasing from $2.5 \%$ (AC) to $62.5 \%$ (CAPFLEX).

\subsection{Oxidative Aging}

A volatile content of $1.4 \%$ was obtained in the simulated aging of the modified asphalt by RTFOT. The specification for performance graded asphalt binder ${ }^{25}$ limits the volatile content from RTFOT to $1 \%$. However, there is no such limit in the polymer asphalt binder specification ${ }^{26}$.

The influence of aging on the characteristics of the modified asphalt was studied by FTIR spectrometry. The FTIR spectra before and after RTFOT are illustrated in Fig. 1 while the main representative bands are given in Table 2 .

The asphalt binder displayed physical and chemical changes when subjected to a thermal-oxidative process. These changes may be caused by the loss of volatiles or specimens of low molecular weight, or even by the formation of hydrogen bonds. The formation of carbonyl groups was observed, coupled with increased absorption at a frequency of $1650 \mathrm{~cm}^{-1}$, relating to $\mathrm{C}=\mathrm{O}$ stretching as a result of $\mathrm{AC}$ oxidation. The absorption at the frequency $1160 \mathrm{~cm}^{-1}$ was attributed to anhydride groups also formed after oxidation. A small

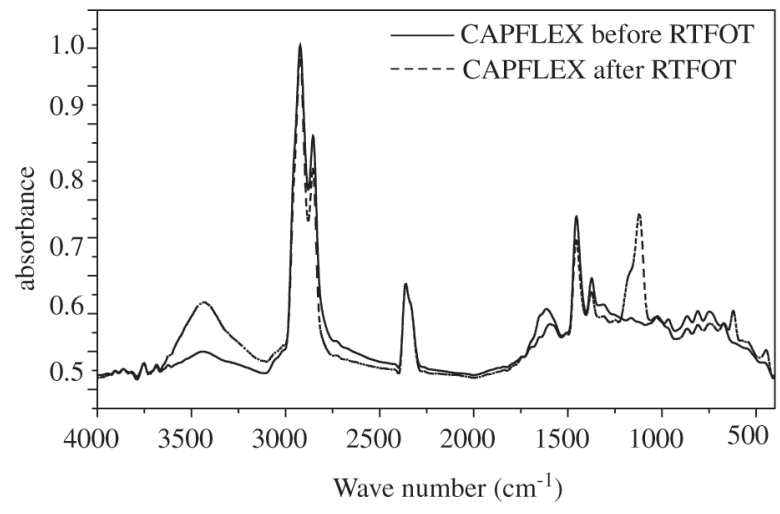

Figure 1. CAPFLEX infrared spectra before and after RTFOT.

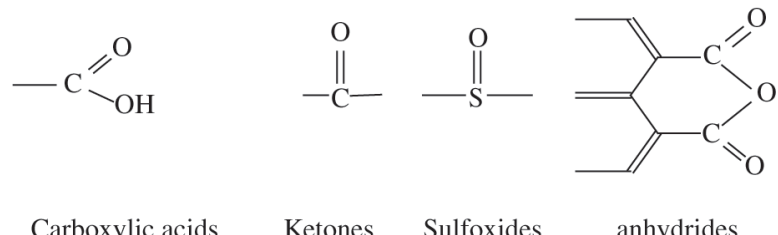

Figure 2. Types of oxidation products formed in asphalt binders during aging.

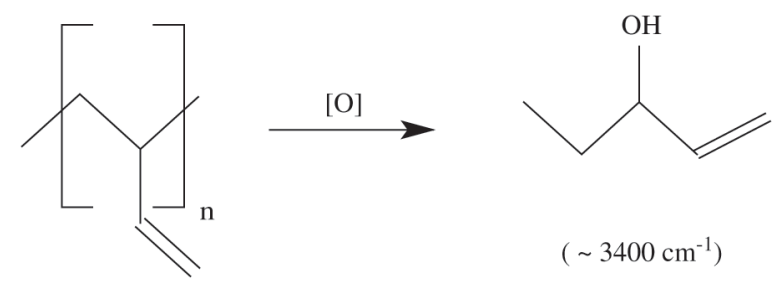

Figure 3. Oxidation of polybutadiene.

number of sulphoxide groups, characterized by the band at the $1030 \mathrm{~cm}^{-1}$ frequency ( $\mathrm{S}=\mathrm{O}$ stretching), were also noted. Very small bands that appeared at 900 to $700 \mathrm{~cm}^{-1}$ were attributed ${ }^{28}$ to the styrene part of the SBS co-polymer. An increase was also observed in the intensity of the band at 3400 $\mathrm{cm}^{-1}$ (OH stretching), which was related with oxidation of the polybutadiene portion in the copolymer. These attribu- 
tions were based on the oxidation products typically formed in asphaltic binders upon aging ${ }^{29}$ and to oxidation of the polybutadiene ${ }^{27}$ illustrated in Figs. 2 and 3, respectively.

\subsection{Thermal Analysis}

\subsubsection{DSC}

The CAPFLEX DSC curve was examined to evaluate its physical characteristics, which depend on aspects such as the refined petroleum source and the petroleum refining process $^{30,31}$. Figure 4 shows the phase transitions observed. At very low temperatures $\left(-30^{\circ} \mathrm{C}\right)$, the increase in heat capacity can be attributed to the glass transition temperature taken at midpoint. Two exothermic effects $\left(\sim-20^{\circ} \mathrm{C}\right)$ occurred above $\mathrm{Tg}$, most likely due to the crystallization of species that do not crystallize during cooling. The melting transition $\left(\Delta \mathrm{H}_{0 \mathrm{bs}}=-823 \mathrm{~mJ} / \mathrm{g}\right)$ was indicated by a broad endothermic event at $25^{\circ} \mathrm{C}$, which corresponded to the dissolution of crystallized fractions in the hydrocarbon matrix. The crystalizable fractions content was also quantified as previously described, showing a value of $0.41 \%$, which is considered small ${ }^{32}$. This result was close to that reported in the literature for the $\mathrm{AC}$ refined from Boscan Petroleum $(\sim 1 \%)^{33}$, considered an AC with very good paving properties. The extent of crystallizable fractions is commonly associated with the presence of wax content in AC, which is responsible for the problem of pavement exudation and inappropriate thermal susceptibility.

\subsubsection{TGA}

Figure 5 shows the thermogravimetric curves of CAPFLEX in $\mathrm{N}_{2}$ (inert) and an oxidative atmosphere.

Table 3 lists the events that occurred during the experiment. A decrease in the amount of residues was observed when CAPFLEX was subjected to an oxidative atmosphere. The initial decomposition temperature $\left(\mathrm{Td}_{\mathrm{i}}\right)$ remained unaltered. Under an inert atmosphere, a single decomposition event was observed, whereas four events were observed in the oxidative atmosphere. The first event presented a decomposition temperature (Td) of approximately $360^{\circ} \mathrm{C}$. The other events took place at decomposition temperatures of

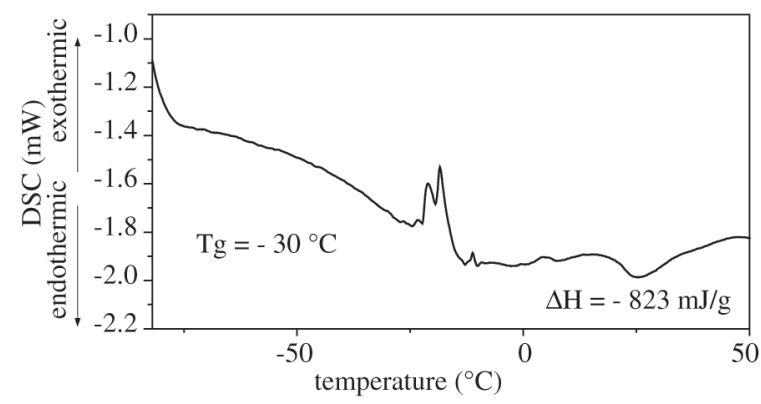

Figure 4. DSC curve of CAPFLEX in an inert atmosphere.
382, 450 and $546{ }^{\circ} \mathrm{C}$, respectively. At temperatures above the decomposition of CAPFLEX, there was a strong reactivity between the decomposition products and the oxygen. The complex structure of the bitumen ${ }^{27}$ (Fig. 6) was composed of unsaturated structures presenting a high reactivity with oxygen.

\subsection{Activation Energy}

Table 4 shows the dependence of the apparent activation energy $\left(E_{a}\right)$, calculated by the Ozawa method, on the degree of decomposition extracted from TGA curves.

It was found that, at the beginning of the decomposition (0-20\%), the CAPFLEX showed similar thermal stabilities in air and nitrogen atmospheres. However, distinct $\mathrm{E}_{\mathrm{a}}$ values were observed after $20 \%$ of decomposition, which were attributed to the complex behavior of the CAPFLEX decomposition process in the oxidative atmosphere.

\section{Conclusions}

The physical characterization of CAPFLEX showed modified asphalt with greater penetration than the unmodi-

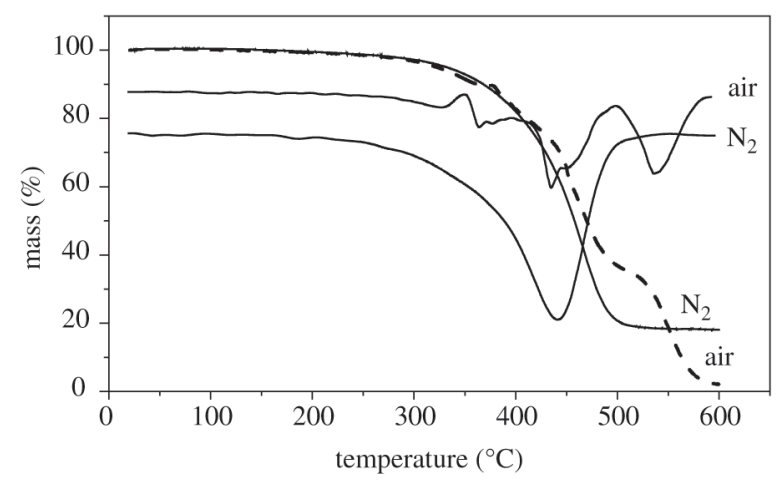

Figure 5. TG and DTG curves of CAPFLEX in air and $\mathrm{N}_{2}$ atmospheres.

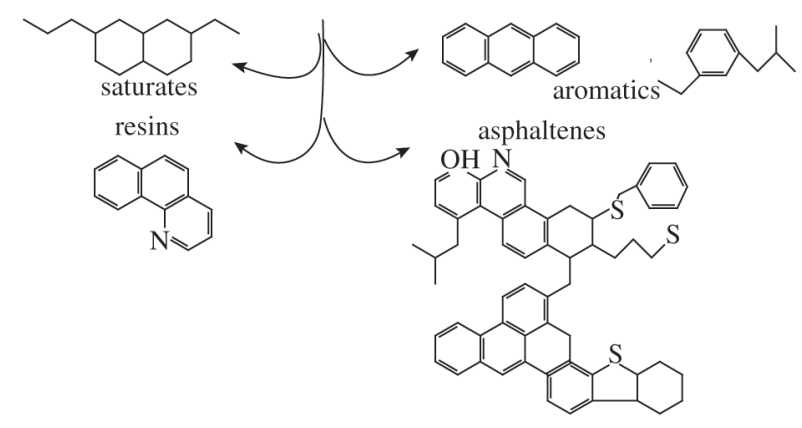

Figure 6. Representative structures of the four bitumen fractions: saturates, aromatics, resins and asphaltenes. 
Table 3. Events from TGA curves of CAPFLEX in air and $\mathrm{N}_{2}$.

\begin{tabular}{|c|c|c|c|c|c|}
\hline Sample & Events & $\operatorname{Td}_{i}\left({ }^{\circ} \mathrm{C}\right)$ & $\operatorname{Td}\left({ }^{\circ} \mathrm{C}\right)$ & $\mathrm{Td}_{\mathrm{f}}\left({ }^{\circ} \mathrm{C}\right)$ & $\%$ Residue \\
\hline CAPFLEX in $\mathrm{N}_{2}$ & single & 214 & 466 & 598 & 18 \\
\hline \multirow{4}{*}{ CAPFLEX in air } & $1^{\text {st }}$ & 214 & 360 & - & 92 \\
\hline & $2^{\text {nd }}$ & - & 382 & - & 81 \\
\hline & $3^{\text {rd }}$ & - & 450 & - & 36 \\
\hline & $4^{\text {th }}$ & - & 546 & 598 & 3 \\
\hline
\end{tabular}

Table 4. Apparent activation energy $\left(\mathrm{E}_{\mathrm{a}}\right)$ as a function of the degree of decomposition of CAPFLEX under inert and oxidative atmospheres.

\begin{tabular}{ccc}
\hline $\begin{array}{c}\text { Decomposition } \\
(\%)\end{array}$ & $\begin{array}{r}\mathrm{E}_{\mathrm{a}} \text { under oxidative } \\
\text { atmosphere } \\
(\mathrm{kJ} / \mathrm{mol})\end{array}$ & $\begin{array}{c}\mathrm{E}_{\mathrm{a}} \text { under inert } \\
\text { atmosphere } \\
(\mathrm{kJ} / \mathrm{mol})\end{array}$ \\
\hline 10 & 122 & 122 \\
20 & 125 & 125 \\
30 & 208 & 147 \\
40 & 224 & 168 \\
50 & 235 & 184 \\
60 & 360 & 193 \\
70 & 200 & 204 \\
80 & 119 & 210 \\
\hline
\end{tabular}

fied AC. Its thermal susceptibility and elastic recovery were also improved. CAPFLEX showed a small value of crystallized paraffins at a low temperature, suggesting asphalt with appropriate paving properties and reduced susceptibility to thermal cracking. The aged CAPFLEX revealed an increase in carbonyl, hydroxide and sulphoxide groups due to oxidation, which induced structural modifications. The thermal degradation mechanism appears to be distinct in oxidative and inert atmospheres.

\section{Acknowledgments}

The authors thank Petrobras BR Distribuidora for the samples and Petrobras/Lubnor for its technical support during the laboratorial tests. The first author is also indebted to the National Petroleum Agency (ANP) for its financial support of this work.

\section{References}

1. Isacson, U.; Xiaohu, L. Journal of Materials Science, v. 34, p. 3737-3745, 1999.

2. Green, J.B.; Yu, S.K.T.; Pearson, C.D.; Reynolds, J.W. Energy \& Fuels, v. 7, p. 119-126, 1993.

3. Rajesh, V. et al., Polymer, v. 43, p. 4667-4671, 2002.

4. Xiaohu, L.; Isacson, U. Polymer Testing, v. 20, p. 77-86, 2001.

5. Isacsson, U.; Xiaohu, L. Constuction Building Material, v. 11, p. 23-29, 1997.

6. Gordon, A. Fuel, v. 82, p. 1709-1719, 2003.

7. Xiaohu, L.; Isacson, U. Fuel, v. 76, p. 1353-1359, 1997.

8. Wen, G.; Zhang, Y.; Sun, K.; Fan, Y. Polymer Testing, v. 21, p. 295-302, 2002.

9. Leite, L.M.; PhD Dissertation, Instituto de Macromoléculas Professora Eloísa Mano da Universidade Federal do Rio de Janeiro, 1999.

10. Brulé, B.; Planche, J.P.; King, G.N.; Claudy, P.; Létoffé, J.M. Fuel Science and Technology International, v. 9, p. 71-91, 1991.

11. Fawcett, A.H.; McNally, T.; McNally, G.M.; Andrews, F.; Clarke, J.; Polymer, v. 40, p. 6337-6349, 1999.

12. Claudy, P.M.; Létoffé, J.M.; Martin, D.; Planche, J.P. Thermochimica Acta, v. 324, p. 203-213, 1998.

13. Masson, J.F.; Polomark, G.M. Thermochimica Acta, v. 374, p. 105-114, 2001.

14. SHRP Superior Performing Asphalt Pavements (Superpave): The Product of SHRP Asphalt Research Program. Strategic Highway Research Program A-410, National Research Council, Washington, DC, 1994.

15. Annual Book of ASTM Standards D 6373, Standard Specification for Performance Graded Asphalt Binder, 1999.

16. Annual Book of ASTM Standards D 5, Standard Test Method for Penetration of Bituminous Materials 1995.

17. Annual Book of ASTM Standards D 36, Standard Test Method for Softening Point of Bitumen (Ring and Ball Apparatus), 1995.

18. Annual Book of ASTM Standards D 6084, Standard Test Method for Elastic Recovery of Bituminous Material by Ductilometer 1997.

19. Annual Book of ASTM Standards D 4402, Standard Test Method for Viscosity Determinations of Unfilled Asphalts Using the Brookfield Thermosel Apparatus 1995.

20. Lucena, M.C.C. Master's Thesis, Universidade Federal do Ceará 2001.

21. Annual Book of ASTM Standards D 140, Standard Practice for Sampling Bituminous Materials, 2001.

22. Claudy, P.; Létoffé, J.M.; King, G.N.; Planche, J.P.; Brulé, B. Fuel Science and Technology Int'l, v. 9, p. 7192, 1991.

23. Brulé, B.; Planche, J.P.; King, G.N.; Claudy, P.; Létoffé, 
J.M. Symposium on Chemistry and Characterization of Asphalts $-200^{\text {th }}$ National Meeting, American Chemical Society, Washington D.C., USA, p. 26-31, 1992.

24. Silva, L.S.; Forte, M.C.; Cardozo, N.S.M. Anais do $6^{\circ}$ Congresso Brasileiro de Polímeros, p. 820-823, 2001.

25. Annual Book of ASTM Standards D 6373, Standard Specification for Performance Graded Asphalt Binder 1999.

26. Annual Book of ASTM Standards D 5892, Standard Specification for Type IV Polymer-Modified Asphalt Cement for Use in Pavement Construction 1996.

27. Masson, J.F.; Pelletier, L.; Collins, P. Journal of Applied Polymer Science, v. 79, p. 1034-1041, 2001.
28. Xiaohu, L.; Isacson, U. Fuel, v. 77, p. 961-972, 1998.

29. Petersen, J.C. Transportation Research Record, v. 999, p. 13-30, 1984.

30. Jiménez-Mateos, J.M.; Quintro, L.C.; Rial, C. Fuel, v. 75, p. 1691-1700, 1996.

31. Al-Sammerrai, F.; Al-Samerrai, D. Thermochimica Acta v. 115, p. 181-188, 1987.

32. Claudy, P.; Létoffé, J.M.; Germanaud, L.; King, G.N.; Planche, J.P.; Ramond, G.; Such, C.; Buisine, J.M.; Joly, G.; Edlanio, A. Transportation Research Board, p. 1-9, 1993.

33. L. Leite, I.; Tonial, M.L.; Gonçalves, R; Constantino, F. A. Jr.; Bastos, A.R. $13^{\circ}$ Encontro de Asfalto do IBP 1996. 